\title{
The Schulich Pain Medicine residency
}

\section{An interview with Dr Geoff Bellingham}

\author{
Dino D'Andrea, Emily N Dzongowski
}

\section{INTRODUCTION}

Dr Bellingham completed his medical school and anesthesiology residency at Western University. He followed this with a fellowship in Chronic Pain Management at the University of Toronto, with a focus on interventional pain management using fluoroscopy and ultrasound guided techniques. Dr Bellingham returned to Western University to work in the Department of Anesthesia and Perioperative Medicine in his capacity as an anesthetist and as a chronic pain specialist. Here at Western, he directs the Pain Clinic at St. Joseph's Health Care and also played a key role in the development of Canada's first Pain Medicine residency program. We had an opportunity to chat with Dr Bellingham and discuss a wide range of topics including his choice of career path, the Pain Medicine residency program, and other pain medicine topics in the context of the current opioid epidemic.

\section{UWOMJ: Why anesthesiology?}

I didn't know I wanted anesthesiology until my third year of medical school when I did my clerkship rotations. Ultimately, what it came down to was that I really enjoyed the people I got to work with in anesthesiology. Based on my experience, what I like to tell medical students looking for career advice is that sometimes a specialty chooses you, rather than you choose the specialty. As an anesthesiologist, you must be comfortable in acute situations and have a certain ease with managing the airways, circulation, breathing and all that kind of resuscitation stuff. I was very happy that I was able to develop that skill set. As a resident, I took pride in the fact that I would always run to the code blues and be comfortable in trying to help the situation. I enjoyed the operating room environment and seeing all the different types of operations, but also liked that anesthesiology could be an avenue to do other things like chronic pain obviously for myself, or intensive care, regional anesthesia, cardiac, simulation, education, and more.

\section{Why chronic pain?}

My interest was sparked early in pre-clerkship while I was in Tobermory doing my rural family medicine experience with Dr George Harper, a local family physician. He was phenomenally knowledgeable and took care of all sorts of stuff there in the community. I was with him for a house call once to see an elderly patient with pain and Dr Harper decided to try this medication called amitriptyline. I remember being surprised that we were attempting to treat pain with an antidepressant! I found this fascinating and thought to myself that pain is such a big issue, and if I can know what this guy knows, then that's a really valuable skill. With that distinct experience in the back of my mind, and then after getting to spend some time in the pain clinic as an anesthesiology resident, I gravitated toward the chronic pain pathway. In chronic pain clinic, you get to see all sorts of really interesting cases, like very unusual pain syndromes. For example, you can have someone with complex regional pain syndrome, a devastating condition where even light touch to the limb can be intensely painful. We still don't understand it well, and I find the mystery around it intriguing.

\section{How is your time divided?}

I'm currently the program director of the Pain Medicine residency program, and in addition I've also served as the Pain Clinic medical director for the past year. I see patients in clinic, do some research and then of course education with our residents where I'm a pretty active teacher. For my average week, I spend Mondays and Tuesdays seeing pain patients in clinic, and on Friday I have time with our fluoroscopy unit where we can do some interventions about the spine. Wednesday is my academic day where I'm performing office based work related to administration of the residency program and Pain Clinic. That leaves Thursday my one day in the operating room. So as you can see, my time is pretty heavily weighted towards pain these days.

\section{What are the pros and cons of anesthesia and pain medicine?}

The operating room environment is what I love about anesthesia. Seeing all my colleagues, those who I had an affinity towards that got me into anesthesia in the first place, is truly a joy. I like keeping my skills sharp for airway management and cardiovascular support, and seeing all the different types of emerging technologies and all the interesting patient cases that come through the door. For chronic pain practice, I like how it's a point of pride that people ask for you by name. You have a singular identity as an expert in this particular field that somebody wants your opinion on. In addition, you get the opportunity to develop a relationship with patients and hopefully take them from a place that's not so great to a place that's a little bit better and more manageable. With operating room anesthesia, you are not able to develop similar patient-doctor relationships as those developed in the pain clinic. The drawback of pain practice is having to become involved in legal or insurance related matters that require report writing, form filling, and other administrative issues that can be very frustrating for both doctors and patients. With pain practice, you've entered into this more administrative realm that you just don't have in the operating room.

\section{How was the Pain Medicine residency started?}

The person who championed this in Canada was Dr Pat Morley-Forster, the previous Pain Clinic lead and fellowship 
director here at Western. Over the course of ten years, she and other pain specialists in Canada lobbied and were successful in developing a Pain Medicine residency program. Dr Morley-Forster did all the ground work with the other founding members, and once that was established there was this template from which to build a residency program. I was the fellowship director at the time, and became involved with the residency program's development and getting it accredited by the Royal College. It was a tremendous amount of work, but everyone here at Western was very supportive and enthusiastic about it. Ultimately, Western was the first centre in Canada to roll out a Pain Medicine residency program in 2014, and many other centres in Canada soon followed.

\section{Who enters into the Pain Medicine residency program, and how is it structured?}

You enter into the program after a five-year residency in areas like anesthesia, neurology, physical medicine, emergency medicine, or internal medicine. Other specialties can also be eligible but require approval by the specialty committee of the Royal College. Currently, I have four residents: two anesthetists, one physiatrist, and one neurosurgeon. The program itself is a full two years consisting of twenty-six blocks. Although, it doesn't have to be a full two years because you can get credit from previous rotations, so realistically about a year and a half is reasonable.

\section{What is the difference between a pain residency and a pain fellowship?}

Pain fellowship programs are not required to provide their trainees with any particular set of clinical experiences. Some programs may offer more interventional opportunities, while others could be more clinic based. My fellowship in Toronto provided me with a mix of interventional and office-based outpatient experience. However, there was no set curriculum. For example, I had to advocate for my own addiction medicine clinical experience since my supervisor did not plan for it. In contrast, a Royal College accredited Pain Medicine residency has a much greater breadth of clinical experience, which program directors are held accountable for providing. There are 13 blocks of pain clinic experience, in addition to mandatory rotations in addiction medicine, psychiatry, neurology, acute pain service, cancer pain, pediatric pain, and musculoskeletal/rheumatology clinics. Selective experiences can also include rotations such as sleep medicine, something very relevant for the patients of a practicing pain physician. Residents can also obtain fluoroscopic or ultrasound-based interventional skills. Ultimately, the residency program is designed to train physicians to be leaders in pain management whether it be administrative, research or education.

Why is a breadth of experience so important in pain medicine?

It's especially important since you learn to tie all of the components of good pain management together, no matter what specialty you come from. For example, an anesthetist would not have the training to manage anxiety and depression, while a psychiatrist would not how to do a nerve block, and a physiatrist would not know how to appropriately dose a patient controlled analgesic pump for acute postoperative pain. Pain management is more than simply learning to put needles into people. You must have some literacy in knowing who you're treating with that needle. For example, if you have someone coming into your clinic after a motor vehicle accident that you think can benefit with some sort of facet joint injection for their whiplash, but at the same time they have this litigation going on, they're suing some person for the crash, they feel wronged, are angry they can't work, and so on. Do you think that your injection is going to be as effective as it could be under these circumstances? The answer is no because you can't inject away injustice. So, what to do about a person like with pain who feels hard done by? Well that's for our pain psychologists to help with, but as the person doing the injection, at least I have a much better sense of who I'm dealing with, and all the multi-faceted issues that need to be dealt with.

\section{What is the role of a pain medicine specialist in combatting the current opioid epidemic?}

We want to help physicians become more comfortable with managing patients on opioids, which includes placing recommendations for our colleagues who may not be so comfortable. There is no secret to good opioid management. We don't have any secrets we keep only in the Pain Clinic, it's all out there in the Canadian National Opioid Use Guidelines. It's about physicians doing their due diligence to have a rational pharmacotherapeutic plan, good responsible prescribing practice, clear education with patients, clear expectations with patients about what opioids can and can't do, and cognisance of long-term effects. This is also what we train our residents to do. It's also important to be aware that a pain medicine specialist isn't synonymous with an addiction medicine specialist. I mean, that's a very distinct category with its own nuances. I think what we need to do in pain medicine is be able to correctly identify an issue or aberrant drug use, stabilize people, make recommendations, and go on to more appropriate treatment.

\section{Do you see graduates of the Pain Medicine residency making an impact on the opioid problem?}

It's early to tell since we've only graduated two or three nationwide, but it's the unique perspective on pain that our residents leave with that I hope gets out there. Injections alone will not take the pain away, nothing could be further from the truth. Injections can help, but only for a short period of time. If you're 42 years old and you want an injection for your back pain, sure it will help, but you can't do that every three months for the rest of your life! Sustainability, talking about other surrounding issues, pacing, multi-disciplinary care, maybe injections here and there to wean opioids, these are all just pieces of a puzzle on how to tackle the problem.

\section{What would you most like to see improved in the field of pain management?}

There needs to be more multi-professional and interdisciplinary 
care. There are lots of different types of pain clinics out there, and just like any other field of medicine, you have a spectrum of really good ones, and others that are not so great. We need to promote education, self-management, multi-disciplinary care. There are some clinics with a heavy focus on injections as the answer to pain, with a lack of patient engagement. If we can turn this around, specifically in Ontario, we can start to turn that ship around and realize that an injection does not address the opioid crisis, and it never will. If someone has an issue with an opioid, you can't inject that away. You have to sit down with them and understand their pain, social circumstances, and many other factors potentially at play. We need more of this. That's really where we need to steer the ship. And that was part of the impetus for the Pain Medicine residency program.

What advice do you have for medical students that are interested in anesthesia or pain medicine?

The main thing is to just get as much experience as possible. For pain medicine specifically, you've GOT to get into the clinic. The interventions can be fun, but you've got to see the complex cases that require multidisciplinary management. You've got to see all the different pain issues - the psychological, the psychiatric, the addiction, the polypharmacy, the social dynamics, the expectation management, and the communication with the team. That's the difficult part. That's the part that you need a good understanding of because if you want to get into it, you have to know what you're getting into. And it's so important that you do that for pain medicine. If you just see the ultrasound or the fluoroscopy and you think "oh, that's pain medicine", you're wrong. Pain medicine should be about teaching people to self-manage, guide them in good choices therapeutically, minimize harm, help to educate them, and along with your allied health colleagues teach them how to live a better life with chronic pain. If you're expecting to get into pain medicine and stomp out pain and cure it when you see it, you're going to be disappointed quickly. That is what you need to understand, and to do so you need to be involved. In short, spend substantial time in the clinic. For anesthesia, the advice is probably the same, get involved, and just get familiar with it as best possible.

\section{We want to hear from you!}

Please take a moment to fill out our reader survey:

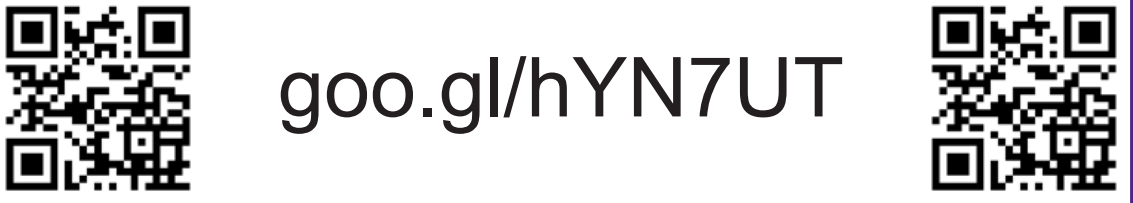

